\title{
Subacute Cutaneous Lupus Erythematosus in Older Man: Case Report
}

\author{
Debora Trindade Martins', Thiago Sande Miguel', Nayrton Kalys Cruz dos Anjos', \\ Sebastião Celio Horta Coelho Filho1, Vinicius Moreira Paladino1, Bruna Sande Miguel2, \\ Vinicius Sande Miguel², Daniel Almeida da Costa1, Livia Cristina de Melo Pino' \\ ${ }^{1}$ The Medical School at the Center of Higher Education of Valença, Valença, Brazil \\ ${ }^{2}$ Unigranrio Medical School, Rio de Janeiro, Brazil \\ Email: professordanielfmv@gmail.com
}

How to cite this paper: Martins, D.T., Miguel, T.S., dos Anjos, N.K.C., Filho, S.C.H.C., Paladino, V.M., Miguel, B.S., Miguel, V.S., da Costa, D.A. and de Melo Pino, L.C. (2017) Subacute Cutaneous Lupus Erythematosus in Older Man: Case Report. Journal of Biosciences and Medicines, 5, 25-33.

https://doi.org/10.4236/jbm.2017.510003

Received: August 21, 2017

Accepted: October 20, 2017

Published: October 23, 2017

Copyright $\odot 2017$ by authors and Scientific Research Publishing Inc. This work is licensed under the Creative Commons Attribution International License (CC BY 4.0).

http://creativecommons.org/licenses/by/4.0/

\begin{abstract}
Systemic lupus erythematosus (SLE) is an autoimmune disease that affects mainly women, presents several clinical manifestations and has no known exact cause. The skin is one of the organs that can be affected, with subacute cutaneous lupus erythematosus (SCLE) being one of the classifications according to cutaneous lupus erythematosus lesions. SCLE is commonly found in young to middle age women and carries characteristics related to sun exposure. In this report, there is a rare case of a male and elderly patient that presents SCLE subgroup initially asymptomatic, with subsequent appearance of macular skin lesions and vitiligo appearance. This is an important case to alert health professionals that the disease can manifest itself and open its clinical profile even in patients of sex and unusual ages.
\end{abstract}

\section{Keywords}

Autoimmune-Disease, Skin, Man, Lupus

\section{Introduction}

Systemic Lupus Erythematosus (SLE) is an autoimmune pathology, with a spectrum of vast clinical manifestations that can affect any system, with greater involvement in female individuals, in a proportion of nine times bigger when compared to male. In United States, the prevalence is approximately 130/100,000, with African Americans Hispanics and Asians being the most frequently affected [1] [2] [3].

Such a disease remains with an unknown etiology, yet it has a strong genetic component with high familial agreement. It is important to remember that en- 
vironmental factors, such as ultraviolet (UV) radiation, stress, medication or infection, viral and hormonal factors can be considered as possible causes and may contribute to the disease onset [4] [5]. One important characteristic is the presence of circulating auto-reactive antibodies that are deposited in tissues such as brain, kidneys and skin, resulting in an inflammatory response with considerable organs damage [4] [6].

It does not have linearity as it progresses, following a course of reaction and remission and, due to its heterogeneity, may vary from patient to patient, making both diagnosis and treatment are challenges [4] [5] [6]. Its clinical manifestations are ample, and may involve any organism component, simultaneously or in stages, during any illness period [2] [7].

To reach the diagnosis, it is of great importance to carry out the research of antibodies or antinuclear factors (ANF) by the indirect immunofluorescence technique. Although this test is not specific, its positivity serves as a screening because of its high sensitivity, the pathology presence is very unlikely if the test result is negative [6] [8] [9] [10]. Furthermore, the search for Anti-DNA, Anti-Sm and antinucleosome can be found in SLE and may help in laboratory characterization [8] [9] [10].

The cutaneous system may be the most affected, since it is involved in up to $85 \%$ of SLE cases and may be the only organ related to cutaneous lupus erythematosus (CLE). Current theories, point to a relation of multiple factors that lead to the cutaneous lupus development, including autoimmune induction, immune system damage and genetic susceptibility [5] [11].

Cutaneous lesions constitute 4 of the 17 new criteria established by the International Systemic Lupus Collaborative Clinics (ISDCC) in 2012, for SLE diagnosis: acute cutaneous lupus, chronic cutaneous lupus, oral ulcers and non-healingalopecia [7]. The patient's history, clinical and laboratory tests, serology and histopathological examination should be the basis for CLE diagnosis [11] [12] [13].

CLE lesions classification is related to clinical, histological and immuno-serological criteria, such as: Acute Cutaneous Lupus Erythematosus (ACLE); Subacute Cutaneous Lupus Erythematosus (SCLE); Chronic Cutaneous Lupus Erythematosus (CCLE); and Intermittent Cutaneous Lupus Erythematosus (ICLE), the last one, being considered by some authors to be part of CCLE subgroup [5] [7] [14].

Another classification form, proposed by Gilliam, separates the lesions according to their histopathology, being they erythematous specific and nonspecific lesions. Specific ones are usually present only in patients with erythematosus lupus (EL), and may be considered as diagnostic. Non-specific ones are not found in EL, since they can also be observed in other autoimmune diseases [5] [11].

SCLE occurs mainly in women, as well as in SLE, at young or middle-age, and has the characteristic of being highly photosensitive, not being commonly found 
in males in various age groups. Two morphological types of SCLE can be found: polycyclic annular, characterized by presenting squamous erythematous plaques, prone to adhere and form a polycyclic matrix and papulosquamous, which can be manifested by psoriasis or eczema [1] [11] [15].

Lesions found in SCLE are located mainly in areas with sun exposure, as in the upper thorax ("V" distribution), arms and forearms, with symmetrical arrangement, and in the posterior thoracic region upper part, and may be characterized by non-ulcerative hypochromic-erythematous macules. Generally, the face central portion and the scalp are spared. In addition to UV rays, several drugs can induce the onset of SCLE, such as terbinafine converting enzyme inhibitors. Skin lesions are not indurated, but there is a possibility of hypopigmentation with vitiligo [11] [15] [16].

Most SCLE patients tend to have mild systemic symptoms, especially myalgias and arthritis, whereas more severe systemic disorders such as central nervous system lupus and nephritis affect less than $10 \%$ of the cases [11] [17].

The positivity of anti-Ro and anti-La autoantibodies can be found in the SCLE and may also indicate systemic disease. It is common for patients with SCLE to have mild systemic symptoms such as myalgias and arthritis [11] [17].

As a differential diagnosis, dermatomyositis and cutaneous T-cell lymphoma can be mentioned, considering the fact that these lesions have similar appearances [11] [18].

Treatment includes topical sunscreens, moderately potent steroids, pimecrolimus and topical tacrolimus. Situations with more severe involvement can be approached with systemic steroids and hydroxychloroquine [19] [20] [21] [22].

This paper aims to present a rare case of an elderly man with SCLE, with a focus on the diagnosis of this pathology in a patient with sex and age opposed to what is usually found in literature.

\section{Case Report}

Patient JAMT, 69 years old, male, from Valença, RJ, attended the dermatology outpatient clinic at the Luiz Gioseffi Jannuzzi School Hospital, presenting the presence of biliary-like hypochromic erythematous macules in the upper limbs bilaterally, especially in the forearms and in the back of the hands, in the sternal region (in the $\mathrm{V}$ area of the neck) and in face, with a slight involvement around his lips initiated 6 months before, with frame progression (Figures 1-3). He did not have previous pathologies, only made sporadic use of Proton Pump Inhibitor, Omeprazole $20 \mathrm{mg}$, during episodes of epigastralgia. He denied hospitalizations and previous surgeries. According to him, he has a habit of wearing a cap for face protection; however, the other areas remain uncovered, which left them exposed to solar radiation. The patient was asked to perform tests for SCLE, ACLE, vitiligo or paraneoplastic syndrome evaluation. In addition, guidance for use of sunscreen factor 30 .

At the beginning of 2017, patient returns with the exams results, which included the values represented in Table 1. 


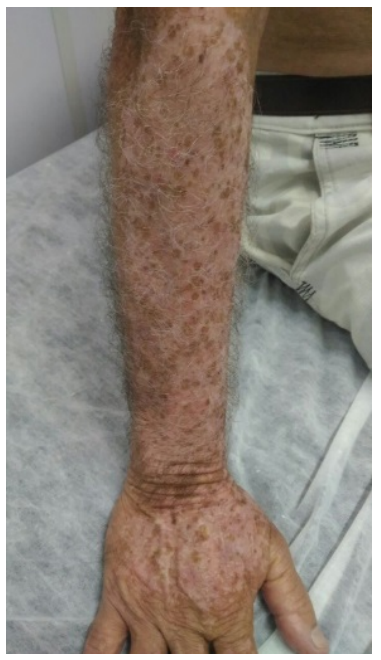

Figure 1. Hypochromic erythematous macules of vitiligo aspect in dorsal region of hands and forearm.

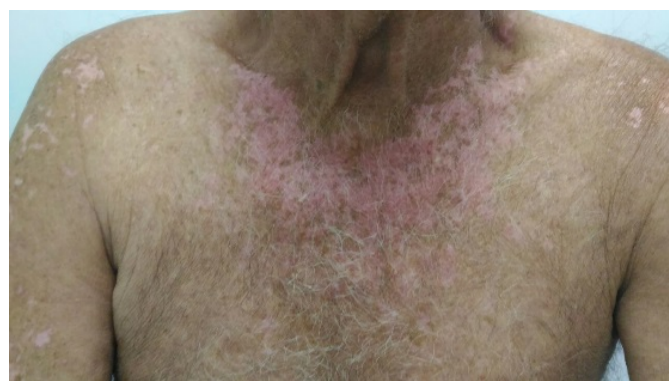

Figure 2. Hypochromic erythematous vitiligo-like erythematous lesions on the upper limbs and $\mathrm{V}$ of the neckline.

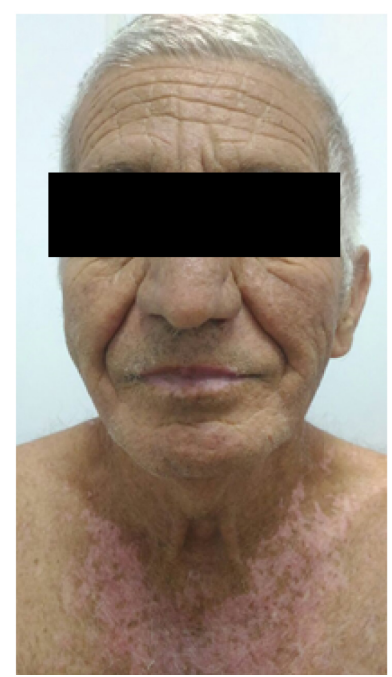

Figure 3. Hypochromic erythematous macules of vitiligo aspect in sternal region, in $\mathrm{V}$ of the neck. Macular lesions in hypochromic regions in the cervical and labial region. 
Table 1. Laboratory tests.

\begin{tabular}{cccc}
\hline Exam & Results & Exam & Results \\
\hline Anti-Ro & $240 \mathrm{U} / \mathrm{ml}$ & Free PSA & $20.4 \mathrm{ng} / \mathrm{ml}$ \\
Anti-Sm & $<7 \mathrm{U} / \mathrm{ml}$ & Total PSA & $249 \mathrm{ng} / \mathrm{ml}$ \\
Anti-La & $<7 \mathrm{U} / \mathrm{ml}$ & Relation free/total & $8 \%$ \\
Anti-DNA & Negative & Free T4 & $0.84 \mathrm{ng} / \mathrm{dl}$ \\
PCR & $<6 \mathrm{U} / \mathrm{ml}$ & TSH & $2.43 \mathrm{mU} / \mathrm{L}$ \\
FAN & $1: 320 \mathrm{U} / \mathrm{ml}$ & C3 & $119 \mathrm{mg} / \mathrm{dl}$ \\
FR & $<8 \mathrm{UI} / \mathrm{ml}$ & C4 & $26 \mathrm{mg} / \mathrm{dl}$ \\
\hline
\end{tabular}

In addition to these, there was a histopathological procedure that included degeneration of the basal layer, epidermis atrophy, lymphocytic exocytosis, perivascular lymphocytic infiltrate, pigmentary incontinence and upper collagen hyalinization, in lane, concluding a condition compatible with SCLE.

The patient therapeutic approach was based on start using hydroxychloroquine $400 \mathrm{mg} /$ day, besides sun protection and investigation of SLE, which was negative.

However, the patient did not continue his clinical follow-up on a regular basis, which made more details of follow-up impossible after an initial approach, as well as greater details of antibody titers and the appearance of their lesions after drug therapy.

It is worth noting that the patient had his doubts clarified about his clinical condition and was exposed about the importance of his case, being this consenting with the publication of the present report, signing the Term of Free and Informed Consent.

\section{Discussion}

On general, the prevalence of autoimmune diseases is much higher in women when compared to the opposite sex, and the young age group is the most affected. SLE is nine times more prone to happen in women when compared to men, as well as SCLE, which also predominates in female subjects [1] [2] [4]. Women, especially those of young age, are the most likely to have autoimmune disease, as evidenced in the literature. The report refers to a man in old age, 69 years, which makes the present study atypical. This can be confirmed by the fact that the patient is male and elderly, which is the opposite of what is found in studies for autoimmune conditions, such as SCLE, both by sex and age group.

Commonly, patients with SCLE have some milder systemic symptoms, in addition to the fact that they have cutaneous involvement in their subacute form, they have diffused, non-ulcerative erythematous lesions that predominate in the upper limbs and trunk upper part, with face usually being spared [2] [5] [8]. Considering that SCLE may or may not be related to lupus systemic form, the patient does not escape the usual when it is revealed an asymptomatic condition onset. However, it presents skin lesions characteristic of subacute lupus, hy- 
pochromic erythematous macules that are located in both the upper limbs and in sternal region, areas more exposed to solar radiation. The face is almost spared because the use of cap, which avoids sun's incidence in this area, excluding a small region close to the lips, which is configured as a transition part between the area protected by the cap and the photo exposed area.

There is involvement of the hands dorsum and proximal phalanges bilaterally, and the interphalangeal joints are spared, as can be found in the disease this place of cutaneous involvement [10] [23] [24].

Considering that the values for Anti-Ro are reactants when higher than 10.0 $\mathrm{U} / \mathrm{mL}$ [6] [8] [11], this patient presents $240 \mathrm{U} / \mathrm{mL}$, noting the relation between anti-nucleus antibody and SCLE, corroborating with the diagnosis. In addition to this, one can search for Anti-La [6] [8] [11], which shows positivity when above $10.0 \mathrm{U} / \mathrm{mL}$, and the patient has a value lower than $7.0 \mathrm{U} / \mathrm{mL}$, which can also be present in the disease and comes according to the literature, because Anti-La is found in only approximately $10 \%$ of lupus carriers [6] [8] [11].

Patients with autoimmune pathologies tend to have moderate (1/160 and $1 / 320)$ and high $(\geq 1 / 640)$ titers, while those who are healthy have low titers (1/80), but there are exceptions [6] [8] [9] [11]. The result found in the patient's FAN test reveals that it can be classified as a moderate degree, $1 / 320$, which shows the condition autoimmune nature, being highly sensitive to these conditions, so it is fundamental for further investigation.

Anti-DNA antibodies are considered as SLE markers, as are Anti-Sms [6] [8] [11]. The patient results emphasize the case rarity, since the first examination was negative, and the second below $7.0 \mathrm{U} / \mathrm{mL}$ being non-reactive, once these markers are very found in this pathology.

Deficiencies of C3 and/or C4 may indicate SLE or SCLE, but may also be related to other diseases [6] [8] [25]. In the case presented, the patient remains with its values within the normal range, being C3 $119 \mathrm{mg} / \mathrm{dL}$ and C4 $26 \mathrm{Mg} / \mathrm{dL}$, whereas the reference values for $\mathrm{C} 3$ and $\mathrm{C} 4$ are respectively $90-180 \mathrm{mg} / \mathrm{dL}$ and $19-52 \mathrm{mg} / \mathrm{dL}$.

Histological findings vary for each subtype, but characteristics such as vacuolar or hydropic alteration and lymphocytic infiltrates are generally present in CLE cases [11] [23] [24], being found in the patient a lymphocytic infiltrate compatible with the pathology. In addition to these findings, some authors propose histopathological criteria to determine SCLE diagnosis, such as lymphocytes suprabasal exocytosis, prominent epidermal atrophy, minimal or absent basement membrane zone thickening [2] [11] [23] [24]. This case patient, presents a histopathological finding of degeneration of the basal layer with epidermal region atrophy, perivascular lymphocytic infiltrate and lymphocytic exocytosis, being concluded a SCLE diagnosis.

SCLE may be induced or aggravated by certain drugs, such as Proton Pump Inhibitors, Thiazide Diuretics, and Calcium Channel Blockers [26] [27]. The patient used the Proton Pump Inhibitor, Omeprazole $20 \mathrm{mg}$, in an irregular man- 
ner, only when he had episodes of epigaltralgia, which may be a triggering factor of the clinical picture.

Treatment can be done by topical sunscreens, steroids and calcineurin inhibitors, while more severe conditions can be treated with hydroxychloroquine and systemic steroids [28] [29] [30] [31]. The patient was duly approached, being treated with hydroxychloroquine $400 \mathrm{mg} /$ day and together with the use of sunscreen. However, it was not adherent to the therapy and did not follow its outpatient follow-up adequately, and no further information on the succession of the lesions and antibody titers after initiation of pharmacological therapy were collected.

\section{Conclusions}

SLE is a highly complex autoimmune disease presenting the most varied immunopathological disorders. Within the disease context, the most frequent manifestations are the cutaneous lesions, which generate CLE variants, different from each other in relation to the symptoms they can present.

Considering this report's focus, SCLE is one of erythematosus lupus subtype, with clinical, serological, histopathological and even genetic characteristics, distinct from others. They occur in sunlight exposed areas because they are photosensitive regions and affect mostly young or middle-aged women.

In view of the foregoing, it can be inferred that rare cases of this disease can be found, such as the patient described above, which presents variations by sex, age, clinical and laboratory manifestations, and it is fundamental to consider such pathology in differential diagnosis of cutaneous affections, even if the most prevalent epidemiology of the condition is not followed.

\section{References}

[1] Danchenko, N., Satia, J.A. and Anthony MS. (2006) Epidemiology of Systemic Lupus Erythematosus: A Comparison of Worldwide Disease Burden. Lupus, 15, 308-318. https://doi.org/10.1191/0961203306lu2305xx

[2] Lisnevskaia, L., Murphy, G. and Isenberg, D. (2014) Systemic Lupus Erythematosus. Lancet, 384, 1878-1888. https://doi.org/10.1016/S0140-6736(14)60128-8

[3] Muscal, E. and Brey, R.L. (2010) Neurological Manifestations of Systemic Lupus Erythematosus in Children and Adults. Neurologic clinics, 28, 61-73. https://doi.org/10.1016/j.ncl.2009.09.004

[4] Gottschalk, T.A., Tsantikos, E. and Hibbs, M.L. (2015) Pathogenic Inflammation and Its Therapeutic Targeting in Systemic Lupus Erythematosus. Frontiers in Immunology, 6, 550. https://doi.org/10.3389/fimmu.2015.00550

[5] Szczęch, J., Rutka, M., Samotij, D., Zalewska, A. and Reich, A. (2016) Clinical Characteristics of Cutaneous Lupus Erythematosus. Advances in Dermatology and Allergology/Postępy Dermatologiii Alergologii, 33, 13-17. https://doi.org/10.5114/pdia.2014.44031

[6] Marks, S.D. and Tullus, K. (2012) Autoantibodies in Systemic Lupus Erythematosus. Pediatric Nephrology, 27, 1855-1868.

https://doi.org/10.1007/s00467-011-2078-4 
[7] Moura Filho, J.P., Peixoto, R.L., Martins, L.G., et al. (2014) Lupus Erythematosus: Considerations about Clinical, Cutaneous and Therapeutic Aspects. Anais Brasileiros de Dermatologia, 89, 118-125. https://doi.org/10.1590/abd1806-4841.20142146

[8] Vera-Recabarren, M.A., Garcia-Carrasco, M., Ramos-Casals, M. and Herrero, C. (2010) Cutaneous Lupus Erythematosus: Clinical and Immunological Study of 308 Patients Stratified by Gender. Clinical and Experimental Dermatology, 35, 729-735. https://doi.org/10.1111/j.1365-2230.2009.03764.x

[9] Biazar, C., Sigges, J., Nikolaos, P., et al. (2013) Cutaneous Lupus Erythematosus: First Multicenter Database Analysis of 1002 Patients from the European Society of Cutaneous Lupus Erythematosus (EULECS). Autoimmunity Reviews, 12, 444-454. https://doi.org/10.1016/j.autrev.2012.08.019

[10] Gronhagen, C.M., Fored, C.M., Granath, F. and Nyberg, F. (2011) Cutaneous Lupus Erythematosus and the Association with Systemic Lupus Erythematosus: A Population-Based Cohort of 1088 Patients in Sweden. British Journal of Dermatology, 164 1335-1341. https://doi.org/10.1111/j.1365-2133.2011.10272.x

[11] Okon, L.G. and Werth, V.P. (2013) Cutaneous Lupus Erythematosus: Diagnosis and Treatment. Best Practice \& Research Clinical Rheumatology, 27, 391-404.

[12] Freire, E.A.M., Souto, L.M. and Ciconelli, R.M. (2011) Medidas de avaliação em lúpus eritematoso sistêmico. [Assessment Measures in Systemic Lupus Erythematosu.] Revista Brasileira de Reumatologia, 51, 75-80. https://doi.org/10.1590/S0482-50042011000100006

[13] Petri, M., Orbai, A.M., Alarcón, G.S., et al. (2012) Derivation and Validation of the Systemic Lupus International Collaborating Clinics Classification Criteria for Systemic Lupus Erythematosus. Arthritis \& Rheumatology, 64, 2677-2686. https://doi.org/10.1002/art.34473

[14] Vera-Recabarren, M.A., Garcia-Carrasco, M., Ramos-Casals, M. and Herrero, C. (2010) Comparative Analysis of Subacute Cutaneous Lupus Erythematosus and Chronic Cutaneous Lupus Erythematosus: Clinical and Immunological Study of 270 Patients. British Journal of Dermatology, 162, 91-101. https://doi.org/10.1111/j.1365-2133.2009.09472.x

[15] Kuhn, A., Gensch, K., Haust, M., et al. (2011) Photoprotective Effects of a Broad-Spectrum Sunscreen in Ultraviolet-Induced Cutaneous Lupus Erythematosus: A Randomized, Vehicle-Controlled, Double-Blind Study. Journal of the American Academy of Dermatology, 64, 37-48.

[16] Sticherling, M. (2011) Update on the Use of Topical Calcineurin Inhibitors in Cutaneous Lupus Erythematosus. Biologics. Targets \& Therapy, 5, 21-31. https://doi.org/10.2147/BTT.S9806

[17] Obermoser, G., Sontheimer, R.D. and Zelger, B. (2010) Overview of Common, Rare and Atypical Manifestations of Cutaneous Lupus Erythematosus and Histopathological Correlates. Lupus, 19, 1050-1070. https://doi.org/10.1177/0961203310370048

[18] Vasquez, R., Wang, D., Tran, Q.P., et al. (2012) A Multi-Center, Cross-Sectional Study on Quality of Life in Cutaneous Lupus Erythematosus. British Journal of Dermatology, 168, 145-153. https://doi.org/10.1111/j.1365-2133.2012.11106.x

[19] Postal, M., Costallat, L.T. and Appenzeller, S. (2012) Biological Therapy in Systemic Lupus Erythematosus. International Journal of Rheumatology, 9, 578-641.

[20] Kuhn, A., Ruland, V. and Bonsmann, G. (2011) Cutaneous Lupus Erythematosus: Update of Therapeutic Options Part I. Journal of the American Academy of Dermatology, 65, 179-193.

[21] Chang, A.Y. and Werth, V.P. (2011) Treatment of Cutaneous Lupus. Current 
Rheumatology Reports, 13, 300-307. https://doi.org/10.1007/s11926-011-0180-Z

[22] Kuhn, A., Ochsendorf, F. and Bonsmann, G. (2010) Treatment of Cutaneous Lupus Erythematosus. Lupus, 19, 1125-1136. https://doi.org/10.1177/0961203310370345

[23] Verma, S.M., Okawa, J., Propert, K.J. and Werth, V.P. (2014) The Impact of Skin Damage Due to Cutaneous Lupus on Quality of Life. British Journal of Dermatology, 170, 315-321. https://doi.org/10.1111/bjd.12653

[24] Uva, L., Miguel, D., Pinheiro, C., Freitas, J.P., Marques Gomes, M. and Filipe, P. (2012) Cutaneous Manifestations of Systemic Lupus Erythematosus. Autoimmune Diseases, 2012, Article ID: 834291. https://doi.org/10.1155/2012/834291

[25] Mellor-Pita, S., Citores, M.J., Castejon, R., Yebra-Bango, M., Tutor-Ureta, P., Rosado, S., et al. (2009) Monocytes and T Lymphocytes Contribute to a Predominance of Interleukin 6 and Interleukin 10 in Systemic Lupus Erythematosus. Cytometry Part B: Clinical Cytometry, 76, 261-270. https://doi.org/10.1002/cyto.b.20468

[26] Sandholdt, L., Laurinaviciene, R. and Bygum, A. (2014) Proton Pump Inhibitor-Induced Subacute Cutaneous Lupus Erythematosus. The British Journal of Dermatology, 170, 342-351. https://doi.org/10.1111/bjd.12699

[27] Aggarwal, N. (2016) Drug-Induced Subacute Cutaneous Lupus Erythematosus Associated with Proton Pump Inhibitors. Drugs-Real World Outcomes, 3, 145-154. https://doi.org/10.1007/s40801-016-0067-4

[28] Chang, A.Y., Piette, E.W., Foering, K.P., Tenhave, R.R., Okawa, J. and Werth, V.P. (2011) Response to Antimalarials in Cutaneous Lupus Erythematosus: A Prospective Analysis. Archives of Dermatology, 147, 1261-1267. https://doi.org/10.1001/archdermatol.2011.191

[29] Frances, C., Cosnes, A., Duhaut, P., et al. (2012) Low Blood Concentration of Hydroxychloroquine in Patients with Refractory Cutaneous Lupus Erythematosus: A French Multicenter Prospective Study. Archives of Dermatology, 148, 479-484. https://doi.org/10.1001/archdermatol.2011.2558

[30] Chang, A.Y., Ghazi, E., Okawa, J. and Werth, V.P. (2013) Quality of Life Differences between Responders and Nonresponders in the Treatment of Cutaneous Lupus Erythematosus. JAMA Dermatology, 149, 104-106. https://doi.org/10.1001/2013.jamadermatol.467

[31] Grönhagen, C.M., Fored, C.M., Linder, M., et al. (2012) Subacute Cutaneous Lupus Erythematosus and Its Association with Drugs: A Population-Based Matched Case-Control Study of 234 Patients in Sweden. British Journal of Dermatology, 167, 296-305. https://doi.org/10.1111/j.1365-2133.2012.10969.x 